\title{
Suppression of thrust fluctuation of doubly-fed linear motor
}

\author{
Ying WANG*, Kunlun ZHANG, Mi ZHOU \\ Key Laboratory of Magnetic Levitation Technologies and Maglev Trains (Ministry of Education of China), School of Electrical En- \\ gineering, Southwest Jiaotong University, Chengdu 610031, China
}

\begin{abstract}
Because the mover and stator of a doubly-fed linear motor are both equipped with three-phase windings, the motor enables contactless energy to be transferred from the stator to the mover. Thus, when a doubly-fed linear motor is used in the linear driving system of trains, neither an overhead line nor a third rail is needed. However, the doublyfed motor will lead to more severe thrust fluctuation than the unilateral motors. In order to overcome this shortcoming, the thrust fluctuation of the doubly-fed motor should be analyzed. In this paper, an expression for motor thrust is derived. It points out that the slot effect caused by the slotted structure is the main reason for the increase of thrust fluctuation. The method of adopting unequal pole pitch and unequal slot numbers per pole per phase of stator and mover, is proposed to weaken the slot effect when designing the motor slot parameters. Three different motor models are simulated by ANSOFT. The proposed method results in a motor thrust fluctuation coefficient of $8.4 \%$, compared to $49.4 \%$ for the conventional method. Therefore, the motor's thrust fluctuation is effectively suppressed by the proposed method.
\end{abstract}

Key words: doubly-fed linear motor; thrust fluctuation; slot effect; fractional slot

(C) 2012 JMT. All rights reserved.

\section{Introduction}

$\mathrm{T}$ he motor used in the linear driving system of trains is generally unilateral linear motor of a flat type. Its stator is made up of three-phase winding and core, and its mover is made of copper, aluminum, or composite [1]. This structure can control the train's traction and braking, but cannot transfer energy from the stator to the mover.

Doubly-fed linear motors can transfer contactless energy from the stator to the mover, and neither an overhead line nor a third rail is needed when it is used in linear driving system. In the doubly-fed linear motor, both the stator and mover are equipped with three-phase windings [2]. The stator is mounted between the rails, whereas the mover is fixed below the undercarriage of the vehicle. The thrust fluctuation of a doubly-fed motor is more severe than that of a unilateral motor. Therefore, the problem of thrust fluctuation needs to be resolved when doubly-fed motors are used in linear driving system of trains.

There are a lot of methods [3-8] to suppress the thrust fluctuations of motors, such as adopting skewed stator slots, mover oblique pole, magnetic pole inhomogeneous

Received May 21, 2012; revision accepted Jun. 4, 2012

*Corresponding author. Tel.:+86-28-87600773

E-mail: wangying0303@126.com (Y.WANG)

(C) 2012 JMT. All rights reserved

doi: 10.3969/j.issn.2095-087X.2012.02.008 distribution, and the right pole width. However, these methods are not for the doubly-fed linear motor structures.

A novel transportation system NBP (Neue Bahntechnik Paderborn) is under development at the University of Paderborn since 1998. Refs. [9-11] described the features and applications of the doubly-fed motor in the NBP railway system, but did not describe how to suppress the thrust fluctuation.

This paper analyzes the thrust characteristics of the doubly-fed linear motor, and proposes a method to suppress its thrust fluctuation.

\section{Thrust of doubly-fed linear motor}

In the doubly-fed motor, the cores of stator and mover are both stacked and laminated by silicon steel sheet. The stator is mounted between the rail and the mover at the bottom of the train. Three-phase AC windings are installed at both the stator and mover [3], as shown in Fig. 1.

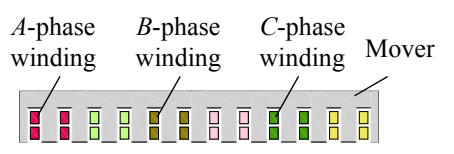

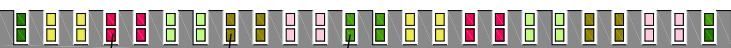

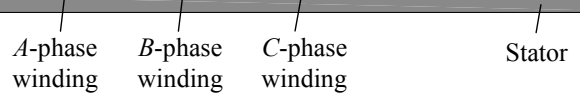

Fig. 1 Stator and mover of the doubly-fed linear motor 
The power frequency of the stator winding is stable and the train speed is controlled by changing the mover's winding frequency.

The electrical current and back electromotive force (EMF) of stator and mover of the ideal linear motor are in the form of sine wave. Suppose $A$-phase currents of the stator and mover windings have the following forms:

$$
\begin{aligned}
& i_{A 1}=I_{m 1} \sin \left(2 \pi f_{1} t-\phi_{1}\right), \\
& i_{A 2}=I_{m 2} \sin \left(2 \pi f_{2} t-\phi_{2}\right),
\end{aligned}
$$

where, $I_{m 1}$ and $I_{m 2}$ are the amplitudes of the $A$-phase current of the stator winding and the mover winding, respectively; $f_{1}$ and $f_{2}$ are the frequencies of the $A$-phase current of the stator winding and the mover winding, respectively; $f_{2}=f_{1}-v / 2 \tau$, where $v$ is the speed of the mover, and $\tau$ is the motor pole pitch; $\phi_{1}$ and $\phi_{2}$ are the initial values of the $A$-phase current of the stator winding and the mover winding, respectively. The amplitudes of the $B$-phase and $C$-phase currents are equal to that of the $A$-phase current, with phase currents lag of $120^{\circ}$ and $240^{\circ}$, respectively.

Ideally, the three-phase winding is completely symmetric; the magnetic field obeys a sinusoidal distribution along the air gap. Suppose that the stator and the mover are of double-stacked winding structures, and the mover displacement is $x$. Then the flux density produced by the motor's stator winding in the stator core is

$$
B_{11}=B_{m 1} \sin \left(2 \pi f_{1} t-\phi_{1}-\pi \frac{x}{\tau}+\frac{\pi}{2}\right),
$$

where

$$
\begin{gathered}
B_{m 1}=\mu_{0} \frac{2 I_{m 1} q_{1} N_{1}}{2 \bar{\delta}} \times 2 \cos \left(\pi \frac{m q_{1}-y_{1}}{m q_{1}}\right)= \\
2 \mu_{0} \frac{I_{m 1} q_{1} N_{1}}{\bar{\delta}} \cos \left(\pi \frac{m q_{1}-y_{1}}{m q_{1}}\right)
\end{gathered}
$$

where, $q_{1}$ is the number of stator slots per pole per phase; $N_{1}$ is the stator coil turns per phase; $m$ is the phase number of the motor; $y_{1}$ is the stator coil pitch, and $\bar{\delta}$ is the equivalent air gap. The flux density produced by the motor's mover winding in the stator core is

$$
B_{21}=B_{m 2} \sin \left(2 \pi f_{1} t-\phi_{2}-\pi \frac{x+v t}{\tau}+\frac{\pi}{2}\right),
$$

where

$$
\begin{gathered}
B_{m 2}=\mu_{0} \frac{2 I_{m 2} q_{2} N_{2}}{2 \bar{\delta}} \times 2 \cos \left(\pi \frac{m q_{2}-y_{2}}{m q_{2}}\right)= \\
2 \mu_{0} \frac{I_{m 2} q_{2} N_{2}}{\bar{\delta}} \cos \left(\pi \frac{m q_{2}-y_{2}}{m q_{2}}\right),
\end{gathered}
$$

where $q_{2}$ is the number of mover slots per pole per phase; $N_{2}$ is mover coil turns per phase; $y_{2}$ is mover coil pitch.

The flux density produced by the motor's stator winding in the mover's core is

$$
B_{12}=B_{m 1} \sin \left(2 \pi f_{2} t-\phi_{1}-\pi \frac{x+v t}{\tau}+\frac{\pi}{2}\right) .
$$

The flux density produced by the motor's mover winding in the mover's core is:

$$
B_{22}=B_{m 2} \sin \left(2 \pi f_{2} t-\phi_{2}-\pi \frac{x}{\tau}+\frac{\pi}{2}\right) .
$$

Both the stator and mover of the doubly-fed linear motor have slots, so the accurate calculation of the equivalent air gap is complicated. It is related to the relative position of the stator to the mover, and also the cogging size. An approximation method can be used to calculate the air gap coefficient [12].

The coefficient of the air gap of the stator is

$$
k_{\delta 1}=\frac{t_{1}}{t_{1}-\frac{b_{s 1}^{2}}{\delta\left(5+b_{s 1} / \delta\right)}},
$$

where, $t_{1}$ is the slot pitch of the stator; $b_{s 1}$ is the slot width of the stator; and $\delta$ is the air gap of the motor.

Coefficient of the air-gap of the mover is

$$
k_{\delta 2}=\frac{t_{2}}{t_{2}-\frac{b_{s 2}^{2}}{\delta\left(5+b_{s 2} / \delta\right)}},
$$

where, $t_{2}$ is the slot pitch of the mover; and $b_{s 2}$ is the slot width of the mover. Then the air-gap coefficient of the motor can be expressed as [13]

$$
k_{\delta}=k_{\delta 1} k_{\delta 2} .
$$

And the motor's equivalent air gap is

$$
\bar{\delta}=k_{\delta} \delta .
$$

According to Eqs. (3) and (4), the flux density in the stator core is

$$
\begin{aligned}
& B_{1}=B_{11}+B_{21}= \\
& \sqrt{\left(B_{m 1}^{2}+B_{m 2}^{2}+2 B_{m 1} B_{m 2} \cos \left(\phi_{1}-\phi_{2}\right)\right) \times} \\
& \sin \left(2 \pi f_{1} t-\pi \frac{x}{\tau}-\phi+\frac{\pi}{2}\right)= \\
& B_{m} \sin \left(2 \pi f_{1} t-\pi \frac{x}{\tau}-\phi+\frac{\pi}{2}\right),
\end{aligned}
$$




$$
\begin{aligned}
& \phi=\tan ^{-1}\left(\frac{B_{m 1} \sin \phi_{1}+B_{m 2} \sin \phi_{2}}{B_{m 1} \cos \phi_{1}+B_{m 2} \cos \phi_{2}}\right) \\
& B_{m}=\sqrt{\left(B_{m 1}^{2}+B_{m 2}^{2}+2 B_{m 1} B_{m 2} \cos \left(\phi_{1}-\phi_{2}\right)\right)} .
\end{aligned}
$$

According to Eqs. (5) and (6), the flux density in the mover core is

$$
\begin{aligned}
& B_{2}=B_{12}+B_{22}= \\
& \sqrt{\left(B_{m 1}^{2}+B_{m 2}^{2}+2 B_{m 1} B_{m 2} \cos \left(\phi_{1}-\phi_{2}\right)\right)} \times \\
& \sin \left(2 \pi f_{2} t-\pi \frac{x}{\tau}-\phi+\frac{\pi}{2}\right)= \\
& B_{m} \sin \left(2 \pi f_{2} t-\pi \frac{x}{\tau}-\phi+\frac{\pi}{2}\right) .
\end{aligned}
$$

The motor is of a doubly-stacked winding structure, and the mover has two monolayer-structured ends. Thus, the $A$-phase winding EMF of stator and mover are

$$
\begin{aligned}
& e_{A 1}=e_{m 1} \sin \left(2 \pi f_{1} t-\phi+\frac{\pi}{2}\right), \\
& e_{A 2}=e_{m 2} \sin \left(2 \pi f_{2} t-\phi+\frac{\pi}{2}\right),
\end{aligned}
$$

where

$$
\begin{aligned}
& e_{m 1}=4.44 K_{d 1} f_{1} B_{m} \tau l_{\delta} N_{1} N_{2}\left(2 p_{2}-1\right), \\
& e_{m 2}=4.44 K_{d 2} f_{2} B_{m} \tau l_{\delta} N_{1} N_{2}\left(2 p_{2}-1\right),
\end{aligned}
$$

where, $K_{d 1}$ is the winding coefficient of the stator; $l_{\delta}$ is the thickness of the core stack; $K_{d 2}$ is the winding coefficient of the mover; and $p_{2}$ is the pole number of the mover.

The active power of the stator and mover are

$$
\begin{aligned}
& p_{e 1}=\frac{3}{2} e_{m 1} I_{m 1} \cos \left(-\phi+\frac{\pi}{2}+\phi_{1}\right)= \\
& \frac{3}{2} e_{m 1} I_{m 1} \sin \left(\phi-\phi_{1}\right), \\
& p_{e 2}=\frac{3}{2} e_{m 2} I_{m 2} \cos \left(-\phi+\frac{\pi}{2}+\phi_{2}\right)= \\
& \frac{3}{2} e_{m 2} I_{m 2} \sin \left(\phi-\phi_{2}\right) .
\end{aligned}
$$

The motor's thrust is

$$
F=\frac{p_{e 1}+p_{e 2}}{v} .
$$

From Eq. (17), the motor's equivalent air gap and its winding coefficient directly influence its thrust fluctuation. If the motor's equivalent air-gap fluctuation or its harmonic winding coefficient is too large, it is possible to cause excessive volatility to the motor's thrust in a running train.

\section{Analysis of harmonic winding coefficient}

The equivalent air-gap fluctuation and harmonic winding coefficient are determined by the cogging parameters. Because of the existence of the slots of stator and mover, when the mover moves, the motor's magnetic reluctance changes, which will produce the thrust fluctuation. The thrust fluctuation of cogging, which is alternating and a function of the structures of the stator and mover, is related to the mover's position. The traditional methods, such as adopting skewed slot, skewed pole, or hexagon magnet, can largely weaken the thrust fluctuation caused by the slot effect. However, these methods will complicate the motor's structure and motor manufacture in practice.

For the sake of convenience, suppose that both the stator and mover of the doubly-fed linear motor have open slots. Air-gap flux density is influenced by cogging, and the tooth harmonic magnetic potential will be produced. When the slot number per pole per phase of mover is equal to that of stator, high harmonic will be strengthened.

When the number of slots per pole per phase $q$ is a fraction, it can be described by

$$
q=\frac{Z_{1}}{2 p m}=b+\frac{c}{d}=\frac{q_{d}}{d},
$$

where, $Z_{1}$ is the total number of the motor's slots; $p$ is the number of pole pairs of motor; $b$ is an integer; $c / d$ is an irreducible proper fraction; and $q_{d} / d$ is an irreducible improper fraction [14]. The fundamental winding coefficient of the fractional slot winding is

$$
K_{d 1}=\frac{\sin \left(\frac{\pi}{2 m}\right)}{q_{d} \sin \left(\frac{\pi}{2 m q_{d}}\right)} .
$$

The winding coefficient of $n$-order harmonic is

$$
K_{d n}=\frac{\sin \left(\frac{n \pi}{2 m}\right)}{q_{d} \sin \left(\frac{n \pi}{2 m q_{d}}\right)} .
$$

The harmonic winding coefficient of the integer slot is equal to the fundamental winding coefficient, so the winding coefficient of high harmonic of the fractional slot is much smaller than that of the integer slot. Then the harmonic fluctuation of thrust is reduced [15]. 
In practice, if the fractional slot is realized by changing the number of slots per pole per phase, motor manufacture will become complicated, so this method is not feasible. Unequal pole pitches between the stator and mover can create a fractional slot. When we keep the pole pitch of the stator unchanged and increase that of the mover, the number of slots per pole per phase of mover becomes a fraction, and the equivalent winding coefficient of each harmonic of the stator winding is smaller than 1, which can suppress the harmonic electromotive force.

Otherwise, when the pole pitches of the stator and mover are equal and the numbers of slots per pole per phase of the stator and mover are equal too, slots of the stator and mover face with each other. Then the fluctuations of the equivalent air gap of the motor will be relatively large. When the pole pitches and the number of slots are unequal, i.e., slots of the stator and the mover do not face with each other, slots are misplaced. This misplacing can reduce the fluctuations of the equivalent air gap. Then from Eq. (17), the motor's thrust fluctuations can be reduced with the structure that pole pitches of the stator and mover are unequal and the slot numbers per pole per phase of the stator and mover are unequal.

\section{FEM simulation}

Because both the stator and mover of doubly-fed motors have teeth and slots, when the mover moves, the thrust fluctuation caused by cogging is much larger than that of unilateral motors. Thus, it is important to design proper cogging parameters of the stator and the mover.

Through the FEM simulation software ANSOFT, three models of doubly-fed motor are established:

(1) model 1: the slot numbers per pole per phase of the stator and mover are both 3 , and the pole pitches of the stator and mover are equal;

(2) model 2: the slot number per pole per phase of the stator is 3 , while that of the mover is 4 , and the pole pitches of the stator and mover are equal;

(3) model 3: the slot number per pole per phase of the stator is 3 , while that of the mover is 4 , and the pole pitches of the stator and mover are unequal (pole pitch of the mover is one slot distance of mover larger than that of the stator).

In these models, motor parameters are set as follows:

stator frequency $f_{1}=50 \mathrm{~Hz}$;

mover frequency $f_{2}=f_{1}-v_{s} / 2 \tau=30 \mathrm{~Hz}$;

mover speed $v_{s}=7.86 \mathrm{~m} / \mathrm{s}$;

the pole pitch of motors $\tau=0.1963 \mathrm{~m}$;

stator current amplitude is $150 \mathrm{~A}$;

mover current amplitude is $100 \mathrm{~A}$;

the phase number of motor $m=3$; when the number of slots per pole per phase is 3 , short pitch of coil $y_{1}=7$;

when the number of slots per pole per phase is 4 , short pitch of coil $y_{1}=9$.

The simulation results are as follows: the thrust fluctuation coefficient of doubly-fed linear motor is $49.4 \%$ for model $1,11.5 \%$ for model 2 , and $8.4 \%$ for model 3 . The thrusts of the three motor models are shown in Figs. 2, 3 and 4, respectively.

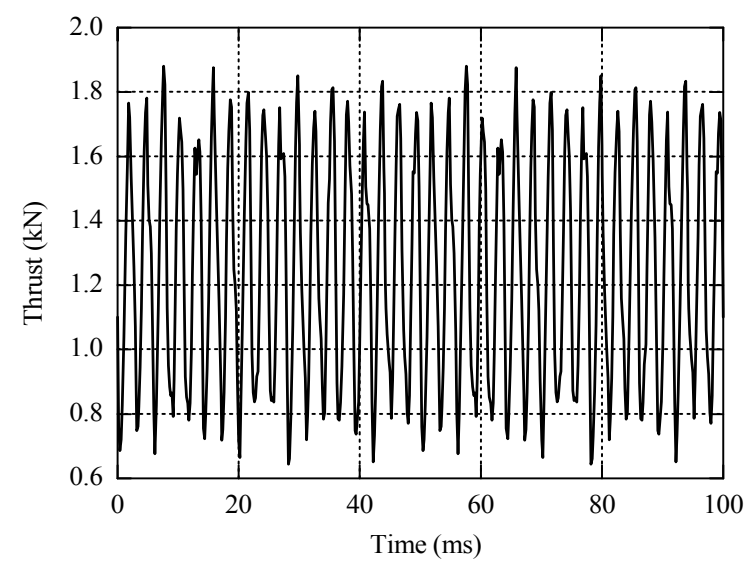

Fig. 2 Motor thrust of model 1

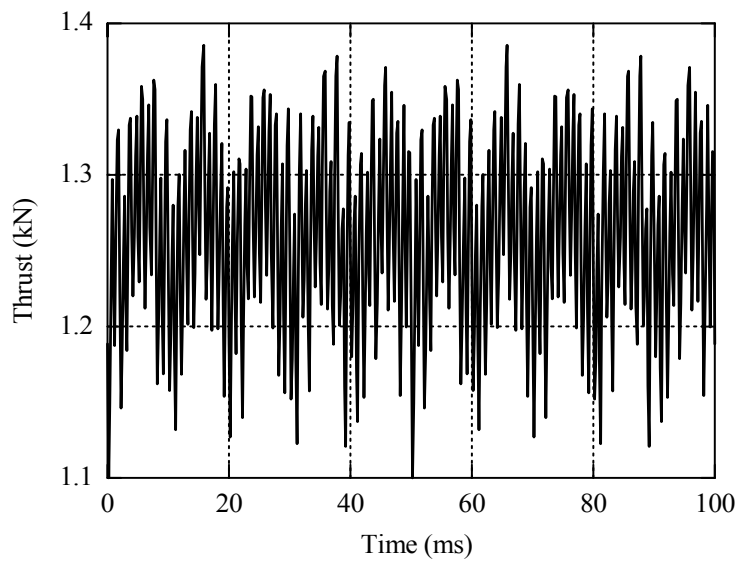

Fig. 3 Motor thrust of model 2

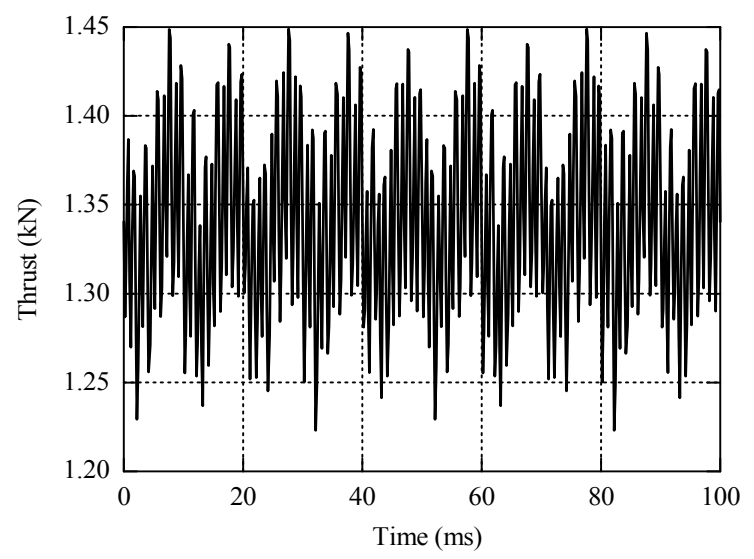

Fig. 4 Motor thrust of model 3 
The results indicate that the thrust fluctuation of the model designed with unequal slot numbers per pole per phase of the stator and mover is smaller than that of the model with equal numbers, and the thrust fluctuation of the model designed with unequaled pole pitches of stator and mover is smaller than that of the model with equal distances.

\section{Conclusion}

Thrust fluctuation of linear motors is mainly produced by the asymmetric winding, slot effect, and end effect. Cores of the stator and mover of a doubly-fed linear motor all have the cogging structure, which will cause a large fluctuation in motor thrust. By designing the cogging parameters of the stator and mover, we find that the method of adopting unequal pole pitches and unequal slot numbers per pole per phase of stator and mover can effectively suppress the motor's thrust fluctuation. The validity of the method is verified using the FEM simulation software ANSOFT. The results show that this method reduces the motor thrust fluctuation coefficient by $8.4 \%$, compared to $49.4 \%$ by the conventional method.

\section{References}

[1] Y.Y. Ye. The Principle and Application of the Linear Motor, Beijing: China Machine Press, 2000 (in Chinese).

[2] T. Schneider, B. Schulz, C. Henke, et al., Energy transfer via linear doubly-fed motor in different operating modes, In: International Electric Machines and Drives Conference, Miami, May 3-6, 2009: 598-605.

[3] N. Bianchi, S. Bolognani, Design techniques for reducing the cogging torque in surface-mounted PM motors, IEEE Transactions on Industry Applications, 2002, 38(5): 1259-1265.
[4] T. Ishikawa, G. Slemon. A method to reduce ripple torque in permanent magnet motors without skewing, IEEE Trans. on Magn., 1993, 29(5): 2028-2031.

[5] T.M. Janhs, W.L. Soong, Pulsating torque minimization techniques for permanent magnet ac motors drives: a review, IEEE Trans. on Ind. Eletron., 1996, 43(5): 321330.

[6] Q.L. Li, X.K. Wang, D. Wu, et al., Thrust fluctuation analysis and reduction of PMSLM, Journal of Tsinghua University (Science and Technology), 2000, 40(5): 33-36 (in Chinese).

[7] Y.P. Sun, G.Y. Li, Method and mechanism analysis of retraining thrust pulsation for long stator linear synchromotors, Transactions of China Electrotechnical Society, 2006, 21(8): 80-82 (in Chinese).

[8] H. Guo, Z.C. Jia, Q.H. Zhang, et al., Analysis of the force of the synchronous linearmotor, Micromotors Servo Technique, 2003, 36(3): 14-17 (in Chinese).

[9] H. Grotstollen, The design of long-stator linear motor drives for railcab test track, Journal of Power Electronics, 2005, 5(2): 166-172.

[10] C. Henke, N. Fröhleke, J. Böcker, Advanced convoy control strategy for autonomously driven railway vehicles, In: Intelligent Transportation Systems Conference, 2006, Toronto, Ontario, Canada, Sep. 17-20, 2006 : 1388-1393.

[11] A. Pottharst, H. Grotstollen, M. Henke, Power supply concept of the longstator linear motor of the NBP-test track, http://wwwlea.uni-paderborn.de/fileadmin/Elektro technik/AG-LEA/forschung/veroeffentlichungen/2002/ 02epe-pemc-pottharst-henke-grotstollen.pdf, 2002-09-09.

[12] S.K. Chen, Motor Design, Beijing: Mechanical Industry Press, 1990 (in Chinese).

[13] H.M. Li, Q.F. Li, Electromagnetic Deceleration Motor, Beijing: Mechanical Industry Press, 1982 (in Chinese).

[14] F.H. Li, T.M. Chen, F.S. Heng, et al., Electro-mechanics, Beijing: Science Press, 1998 (in Chinese).

[15] M.C. Pan, W.G. Tian, D.X. Chen, et al., Electromagnetic force undulation restraining method in MLV using fractional slot, Electric Machines and Control, 2010, 14(11): 63-68 (in Chinese).

(Editor: Dongju DONG) 